\title{
Health impact of dietary neoformed Maillard products in young healthy adults: biological impact of high $v$. low dietary level
}

\author{
J. M. Lecerf ${ }^{1}$, A. Cayzeele ${ }^{1}$, C. Vaysse ${ }^{2}$, A. Galinier ${ }^{3}$, P. Pouillart ${ }^{4}$, F. Tessier ${ }^{4}$ and I. Birlouez-Aragon ${ }^{4}$ \\ ${ }^{1}$ Institut Pasteur, Lille, France, ${ }^{2}$ Institut Technique des Corps Gras, Bordeaux, France, ${ }^{3}$ Centre Hospitalo-Universitaire, \\ Toulouse, France and ${ }^{4}$ Institut Polytechnique LaSalle Beauvais, Beauvais, France
}

Dietary neoformed compounds (NFC) resulting from heat treatment of food are thought to be involved in diabetic complications ${ }^{(1)}$, atherosclerosis $^{(2)}$ and impairment of renal function ${ }^{(3)}$. Carboxymethyllysine (CML), a Maillard NFC, is considered to be the most pertinent indicator of dietary as well as endogenous exposure to NFC because of its stability, its recognized bioactivity through the receptor for advanced glycation end products and its ubiquitous presence in aging and diseased tissues ${ }^{(4)}$.

The aim of the present study was to determine whether a diet that is low in NFC, and specifically low in CML, has a biological impact on carbohydrate and lipid and fatty acid metabolism, inflammatory variables and oxidative stress in young healthy adults.

Sixty-two non-smoking subjects (mean age 20 years) were randomised successively to 4 -week periods on each of the two experimental diets in a cross-over design. The diets were nutritionally equivalent and differed only in the cooking techniques (steam cooking for the low-NFC diet; frying, roasting and grilling for the high-NFC diet that corresponded to the normal diet with minor adaptations).

CML bioavailability data have been reported elsewhere ${ }^{(5)}$. Compared with the steam-cooked diet, which contained three times less CML, a higher $(P<0.002)$ HOMA index was observed with the normal diet, resulting from an increase in fasting insulinaemia $(P<0.01)$ and glycaemia $(P=0.07)$. Plasma TAG $(P<0.01)$, total cholesterol $(P<0.005)$ and HDL-cholesterol $(P<0.0001)$ were higher with the normal diet, but LDL-cholesterol was similar for the two diets. A lower plasma EPA $(P<0.0001)$ and DHA $(P<0.0001)$ was observed with the normal diet, without any change in the linolenic acid content. Both plasma vitamin $\mathrm{C}(P=0.015)$ and vitamin E:cholesterol $(P<0.0001)$ were decreased with the normal diet, whereas plasma ubiquinol $(P=0.013)$ was higher. No change in inflammatory variables or lipid peroxidation was found.

The results indicate that after 1 month on a high-NFC diet compared with a low-NFC steam-cooked diet there is significant impairment of the $n-3$ PUFA profile as well as a trend to insulin resistance associated with higher oxidative stress, which has been shown for the first time in healthy subjects. The direct involvement of NFC is strongly suggested by the similarity between the two diets in relation to confounding factors, the evidence of NFC bioavailability and the significant correlations between biological NFC levels and metabolic variables. The specific role of CML must be clarified.

1. Sandu O, Song K, Weijing C, Zheng F, Uribarri J \& Vlassara H (2005) Diabetes 54, 2314-2319.

2. Vlassara H, Weijing C, Crandall J, Goldberg T Oberstein R, Dardaine V, Peppa M \& Rayfield EJ (2002). Proc Natl Acad Sci USA 99, 15596-15601.

3. Sebekova K, Hofmann T, Boor P, Šebeková K Jr, Uličná O, Erbersdobler HF, Baynes JW, Thorpe SR, Heidland A \& Somoza V (2005) Ann NY Acad Sci 1043, 482-491.

4. Ramasamy R, Yan SF \& Schmidt AM (2007) Mol Nutr Food Res 51, 1111-1115.

5. Birlouez-Aragon I, Saavedra G, Ait-Ameur L, Tessier F, Pouillart P \& Lecerf JM (2007) Proc Nutr Soc 67, OCE, E190 